\title{
Heat transfer and pressure drop in annuli with approximately uniform internal wall temperatures in the transitional flow regime
}

\author{
Dickson D. Ndenguma, Jaco Dirker ${ }^{1}$, Josua P. Meyer \\ Department of Mechanical and Aeronautical Engineering, University of Pretoria, Pretoria, South Africa
}

\section{Highlights}

- Experimental investigation of the transitional flow regime in an annulus for water.

- Heated and cooled inner wall uniform wall temperature conditions are studied.

- Nusselt number, friction factor and critical Reynolds number results are presented.

- Annular dimensions directly impact results - a new geometric parameter is proposed.

- Nusselt number and friction factor correlations are developed.

\begin{abstract}
An experimental study was conducted to determine the lower and upper Reynolds number limits of the transitional flow regime, and the characteristics of the heat transfer coefficients and friction factors for annular passages with different hydraulic diameters and diameter ratios in the transitional flow regime. Water was used in this investigation during isothermal, heating and cooling cases. Four horizontal concentric counter-flow tube-in-tube heat exchangers with conventional inlet geometries were considered to obtain the required data. The flow was both hydrodynamic and thermally developing, and the transitional flow was composed of mixed and forced convection types. The wall temperature on the inner surface of the annular passages was approximately uniform, while the outer surface was isothermal. Average Nusselt numbers were obtained for both the heating and cooling cases, while friction

\footnotetext{
${ }^{1}$ Corresponding author: jaco.dirker@up.ac.za, Mechanical and Aeronautical Department, University of Pretoria, Private Bag X20, Hatfield 0028, RSA.
} 
factors were obtained for heating, cooling and isothermal adiabatic conditions. Isothermal adiabatic condition was considered for reference purposes. The geometric size of the annular passage and direction of the heat flux (heating and cooling cases of annular fluid) had a significant influence on the heat transfer coefficients, friction factors and Reynolds number span of the transitional flow regime. The annular geometric parameters that represent the geometric size of the annular passage were proposed and found to describe the heat transfer coefficient and friction factors well. Subsequently, correlations for predicting the Nusselt numbers and friction factors in the transitional flow regime were developed.

Key words: annulus diameter ratio, hydraulic diameter, transitional flow, mixed convection, Nusselt number, friction factor.

\section{NOMENCLATURE}

$a$

$A_{c}$

$A_{s}$

$C, C_{i s o}, C_{d}$

$c_{p}$

D

$F$

$f$

$\mathrm{Gr}$

$h$

K

$k$
Annular diameter ratio $\left(D_{1} / D_{o}\right)$

Cross-sectional area

Surface area

Coefficients

Specific heat

Diameter

Factor to take into account the dependence on $a$

Friction factor

Grashof number

Convection heat transfer coefficient

Factor to take into account the temperature dependence of fluid properties

Thermal conductivity 


\begin{tabular}{|c|c|}
\hline$L_{d p}$ & Pressure drop length \\
\hline$L_{h x}$ & Heat exchange length \\
\hline$m$ & Correlation exponent \\
\hline$\dot{m}$ & Mass flow rate \\
\hline $\mathrm{Nu}$ & Nusselt number \\
\hline$n$ & Correlation exponent \\
\hline$\Delta p$ & Pressure drop \\
\hline $\operatorname{Pr}$ & Prandtl number \\
\hline$\dot{Q}$ & Heat transfer rate \\
\hline $\operatorname{Re}$ & Reynolds number \\
\hline $\operatorname{Re}_{1}$ & Lower Reynolds number limit of the transitional flow regime \\
\hline $\operatorname{Re}_{2}$ & Upper Reynolds number limit of the transitional flow regime \\
\hline $\mathrm{Ri}$ & Reynolds number \\
\hline$T$ & Temperature \\
\hline $\bar{T}$ & Average temperature \\
\hline$V$ & Average cross-sectional velocity \\
\hline$z$ & Correlation exponent for the viscosity ratio \\
\hline
\end{tabular}

Greek symbols
$\rho \quad$ Density
$\mu \quad$ Dynamic viscosity
$\lambda \quad$ Annular geometric parameter

Subscripts

0 Inner wall of outer tube

$1 \quad$ Outer wall of inner tube 


$\begin{array}{ll}\text { iso } & \text { Isothermal } \\ b & \text { Bulk fluid property } \\ c a & \text { Cooled annulus } \\ d & \text { Diabatic } \\ h & \text { Hydraulic } \\ h a & \text { Heated annulus } \\ i & \text { Inner flow passage } \\ \text { in } & \text { Inlet } \\ \text { iw } & \text { Inner tube wall } \\ \text { LMTD } & \text { Logarithmic mean temperature difference } \\ o & \text { Annular flow passage } \\ \text { out } & \text { Outlet } \\ \text { ow } & \text { Outer tube wall }\end{array}$

\section{Introduction}

Flows in annular passages are of interest to thermal engineers due to their wide range of applications, including their importance in, for instance, tube-in-tube heat exchangers, which are commonly found in several industries. The fluid in the annular passage may either be heated or cooled, depending on the temperature gradient in relation to the heat transfer surface. Different thermal boundary conditions may exist at the heat transfer surface, which influence the heat transfer and pressure drop characteristics, especially if thermal boundary conditions have an impact on buoyancy-driven secondary flow within the passage.

In literature, most investigations are carried out for either uniform wall heat flux or uniform wall temperature conditions [1]. Uniform heat flux conditions are prevalent in solar heating, 
electric heating, electronic cooling and drying technology. Uniform wall temperature conditions are, for instance, relevant to boilers and condensers where one of the fluids undergoes a phase change at the saturation temperature associated with the operating pressure within the relevant heat exchanger flow path. Some familiar engineering applications that involve condensation and boiling are found in refrigeration and steam power plants.

Heat exchangers are often designed to operate in either the laminar or turbulent flow regimes and not in the transitional regime. This could be due to a lack of knowledge of behaviour in the transitional flow regime, or due to an operating condition requirement, or due to the fact that designers want to increase heat transfer coefficients by choosing turbulent flow regime operating conditions. However, due to several reasons, including energy requirements and design and operating constraints, heat exchangers may end up being operated in the transitional flow regime [2-9].

During the thermal design stage of a heat exchanger, correlations are needed to describe the heat transfer coefficient and the friction factor in order to estimate its required geometric size to sustain a desired heat transfer and fluid flow rate. For fully developed forced convection flow in the laminar regime, temperature and fluid flow distributions could either be derived theoretically, or obtained experimentally or determined numerically for some boundary and geometrical cases. For the turbulent flow regime conditions, this can be achieved by correlating experimental or numerical data [10]. However, for the transitional flow regime, data can only be obtained via experimental means, which is often difficult to perform. Therefore, to some extent, the transitional flow regime characteristics have not yet been documented sufficiently to enhance the accuracy of the relevant heat transfer and pressure drop predictions during the design phases of a system. 
In terms of laminar and turbulent flow conditions, several research efforts have been undertaken to investigate heat transfer and pressure drop behaviour in annular passages with different hydraulic diameters and annular diameter ratios. Some of the main purposes of these studies were to specifically determine the effect of the annular diameter ratio, as well as to develop correlations that could best describe the thermal and flow performance of an annular passage in terms of the annular ratio [11-15]. Due to the relatively high heat transfer coefficients obtained during turbulent flow, most of the literature references in this regard are available for turbulent flow cases. In addition, fully developed flow under pure forced convection conditions is often assumed [1].

Among several operating state parameters, the direction of heat transfer has been reported to influence the heat transfer and pressure drop characteristics in a flow passage. This is evident from the well-known Dittus-Boelter correlation [16] for circular tubes where the exponent of the Prandtl number is selected according to the heat transfer direction. For annular flow passages specifically, little research has been conducted on this topic, but some data have been produced by Van Zyl et al. [15] and Prinsloo et al. [14] who investigated the effect of the heat transfer direction (from the inner wall to the annular fluid and vice versa) on the heat transfer coefficient and pressure drop in the turbulent flow regime of annuli of horizontal tubes. It was found that the direction of heat flux (or the relative wall to free stream fluid properties) had an effect on both the heat transfer and friction factor, which could be due to temperature differences between the inner wall and the annular fluid for the heated and cooled cases.

An aspect that complicates flow in the laminar and transitional flow regimes is the impact of buoyancy-driven flow, which may result in mixed convection scenarios where natural 
convection effects are significant enough to impact the heat transfer and pressure drop characteristics in a flow passage. Buoyancy-driven secondary flow often enhances the mixing of the fluid and improves its convective heat transfer ability. Existing results on mixed convection in a horizontal concentric annulus are derived mainly from theoretical studies for laminar flow conditions. These include work by Hattori [11], Nguyen et al. [17], Islam et al. [18], Mirmasoumi and Behzadmehr [19], Mokhtari et al. [20] and Izadi et al.[21]. For experimental studies, only a few references are available in the literature. These include work by Mohammed et al. [22], Ciampi et al. [23] and Lu and Wang [24, 25]. Some of these are briefly discussed here.

For instance, Mohammed et al. [22] conducted a study of mixed convective heat transfer for thermally developing and fully developed laminar air flow in horizontal concentric annuli in the thermal entrance length. They used an inner stainless steel tube, operated at a uniform wall heat flux boundary condition, while the outer wall of the annulus was adiabatic. The effect of secondary flow was found to be significant and gave higher local Nusselt numbers compared to cases without secondary flow. Another important observation was that the heat transfer coefficients for thermally developing flow were considerably greater than the corresponding fully developed flow values over a significant portion of the annulus.

In their studies, Lu and Wang [24, 25] experimentally considered the characteristics of a developing flow with buoyancy-driven secondary flow in narrow annuli in three flow orientations, including a horizontal flow passage layout. Their investigation revealed that heat transfer and flow characteristics in the annular passage differ from those in circular tubes. The transition from laminar to turbulent occurred earlier than it did in circular tubes. The transitional flow regime based on the heat transfer coefficient also occurred earlier than the 
transitional flow regime based on the friction factor. They also reported that, in the laminar flow regime, the isothermal and diabatic friction factors had relatively larger differences than in high Reynolds number regions. Furthermore, at low flow velocities, the buoyancy effects have a relatively large influence on heat transfer coefficients and friction factors in the low Reynolds number region, while little was observed in the high Reynolds number region.

Some parallels can be drawn between the characteristics of circular tube passages and annular flow passages. Comparatively, due to the wider range of application of circular tubes, their characteristics in terms of heat transfer coefficients and friction factors have been extensively investigated and documented. This is especially so for the laminar and turbulent flow regimes [26-30], and to a lesser extent for the transitional flow regime [27, 31-33]. As such, many correlations exist for circular tubes, most of which are available for turbulent flow, followed in number by correlations for laminar flow, and least in number for the transitional flow regime. By summarising the results of earlier research and using a fluid flow model that is valid for all flow regimes, Abraham et al. [31] proposed a friction factor and Reynolds number relationships for fully developed flow in the low Reynolds numbers end of the transitional regime. Gnielinski [34] developed a linear interpolation between the equations for laminar and turbulent in the transitional regime. Some correlations also exist specifically for annular passages. Most of those are for turbulent flow [13-15] and a few for laminar flow [11, 22]. However, not much is known of the characteristics of heat transfer coefficients and friction factors in the transitional regime of an annular passage.

Based on the literature, it is clear that a knowledge gap exists for heat transfer and pressure drop characteristics, especially in the transitional flow regime in annular flow passages when the flow is developing and of the mixed convection type. For this reason, this study is focused on heat transfer and pressure drop characteristics in the annular passages of different annular 
diameter ratios and hydraulic diameters for developing flow associated with buoyancy-driven secondary flow. The thermal boundary condition considered here is of the approximately uniform wall temperature type on the inner wall, and adiabatic on the outer wall. Isothermal adiabatic, heated and cooled annulus cases are considered across a range of water mass flow rates, but specific attention is given to the transitional flow regime. The emphasis in this paper is therefore on the effects of the annular geometric dimensions on the heat transfer coefficients, friction factors and associated critical Reynolds numbers.

\section{Experimental setup}

A schematic representation of the experimental facility is shown in Figure 1. The facility consists of two closed loops: one for cold water and the other for hot water. Different tube-intube heat exchangers were inserted into the flow loops and were used as test sections and facilitated heat transfer from the hot water loop to the cold water loop.

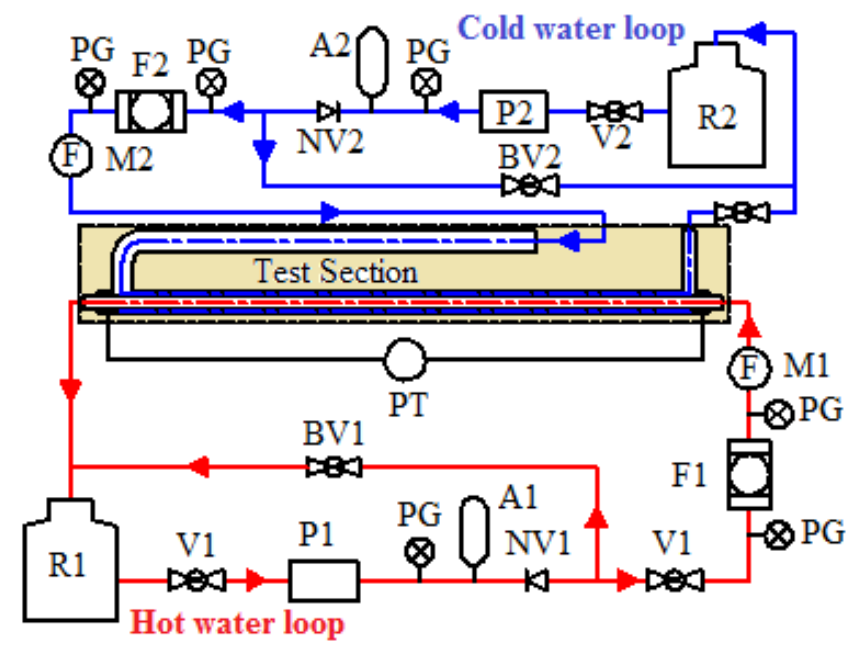

Figure 1: Schematic diagram of experimental setup with test section. The nomenclature of the components is given in the text

A 1 000-litre reservoir (item R1), fitted with a $36 \mathrm{~kW}$ electrical resistance heater, supplied water to the hot water loop (red line in Figure 1). The temperature in the reservoir was 
thermostatically controlled to within $\pm 1{ }^{\circ} \mathrm{C}$. One of two positive displacement pumps (item P1) was used to circulate water through the loop according to the flow rate requirements. The pumps had delivery ranges of $0.032-0.775 \mathrm{~kg} / \mathrm{s}$ and $0.3-1.6 \mathrm{~kg} / \mathrm{s}$, and were electrically controlled. Since flow rates were often required that were much smaller than that for which the pumps were rated, a bypass line with a hand-operated valve (item BV1) was utilised to reduce the flow supplied to the test section. An accumulator (item A1) was installed downstream of the pump to dampen mass flow pulsations and small pressure pulsations to the inlet of the test section. The mass flow rates in the water loop were measured using one of two possible Coriolis flow meters (item M1) with a rated mass flow range of $0-0.607 \mathrm{~kg} / \mathrm{s}$ and $0-1.833 \mathrm{~kg} / \mathrm{s}$ respectively, and measurement error uncertainties of $\pm 0.1 \%$ each. The flow meter selection depended on the required flow rate of a specific test.

The components that made up the cold water loop were very similar to those in the hot water loop. A 5 000-litre reservoir (item R2), connected to a $45 \mathrm{~kW}$ chiller unit, supplied water to the cold water loop (blue line in Figure 1). This temperature was also thermostatically controlled. The same types of pumps and flow meters that were utilised for the hot water loop were also used for the cold water loop. In addition, both loops were fitted with filters (items F1 and F2), pressure gauges (PG), non-return valves (items NV1 and NV2), valves (V1, V2), pressure relief valves, and appropriate pipes and pipe fittings.

For heating tests, cold water was pumped through the annular passage and hot water was pumped through the inner tube (the configuration is shown schematically in Figure 1). By swapping the connections between the test section inlets and outlets, and the two water loops, cooling test could be performed because hot water flowed through the annulus and cold 
water flowed through the inner tube. For isothermal cases, both the inner tube and the annulus were connected to the same flow loop.
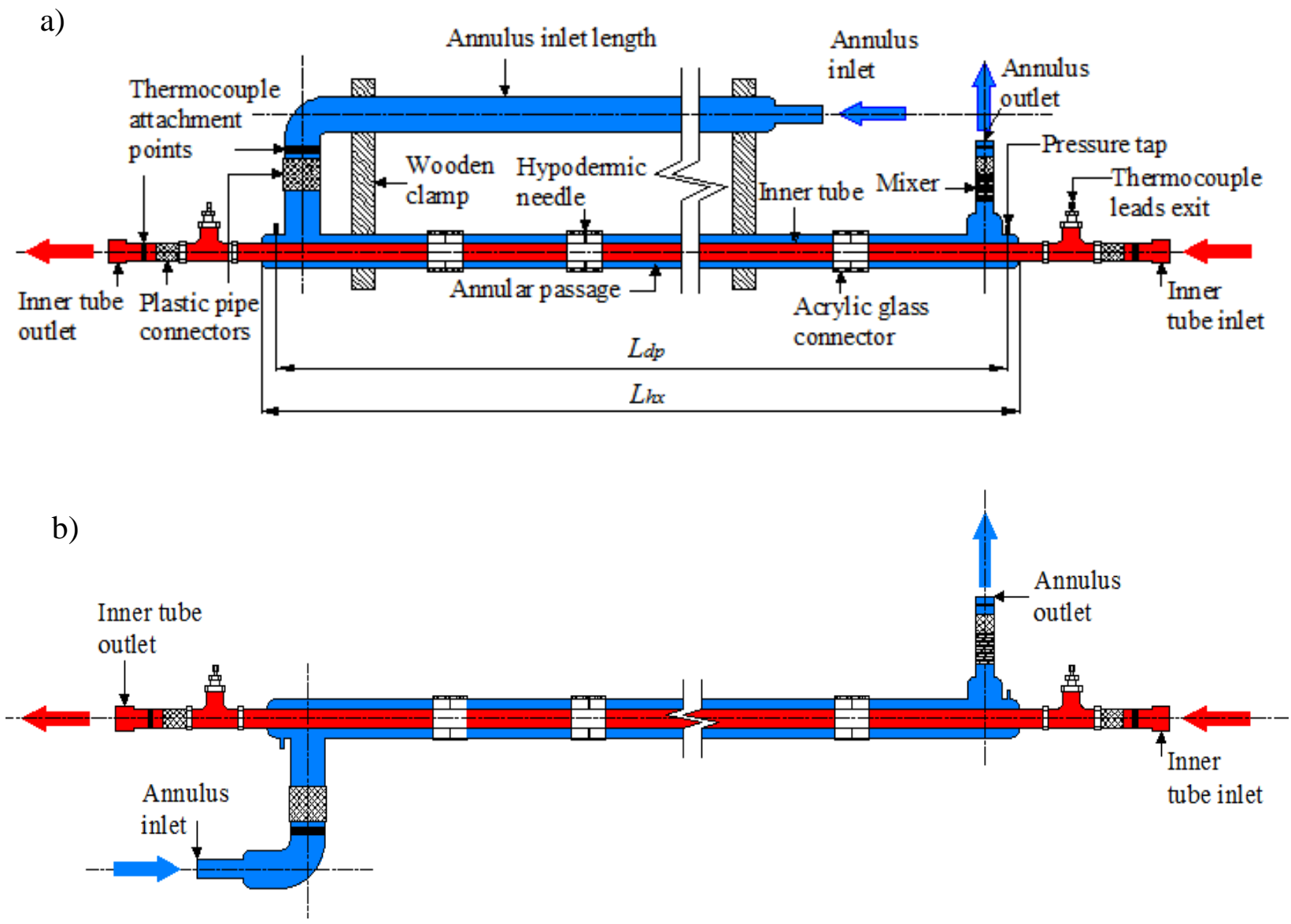

Figure 2: $\quad$ Schematic of the test section similar in configuration to a tube-in-tube heat exchanger test section, but with different annulus inlet configurations: (a) inlet geometry 1; and (b) inlet geometry 1. (Not to scale)

A schematic representation of a test section is shown in Figure 2. Four tube-in-tube heat exchanger test sections were used in this study, each with different inner and outer tube diameters (refer to Table 1). All tubes were hard drawn copper tubes and all the heat exchangers were positioned in a horizontal orientation. Two inner tubes with outer diameters $\left(D_{1}\right)$ of $12.7 \mathrm{~mm}$ and $15.9 \mathrm{~mm}$ respectively were used in combination with two outer tubes with inner diameters $\left(D_{0}\right)$ of $32.9 \mathrm{~mm}$ and $38.88 \mathrm{~mm}$ respectively. This resulted in the four test sections with hydraulic diameters $\left(D_{h}=D_{0}-D_{1}\right)$ of $26.2 \mathrm{~mm}, 23.0 \mathrm{~mm}, 20.2 \mathrm{~mm}$ and 
$17.0 \mathrm{~mm}$, and annular diameter ratios $\left(a=D_{1} / D_{0}\right)$ of $0.327,0.409,0.386$ and 0.483 respectively. In the rest of this paper, these test sections are identified by the numbers TS 1 , TS 2, TS 3 and TS 4, as shown in Table 1 . The heat transfer lengths $\left(L_{h x}\right)$, based on the wetted annulus surface area over which heat transfer could occur, were either $5.06 \mathrm{~m}$ or $5.08 \mathrm{~m}$, and resulted in length-to-diameter ratios $\left(L_{h x} / D_{h}\right)$ ranging from 193.3 to 298.8.

Table 1: $\quad$ Test section dimensions arranged in descending order of $D_{h}$

\begin{tabular}{|c|c|c|c|c|c|c|c|c|}
\hline $\begin{array}{c}\text { Test } \\
\text { section } \\
(\mathrm{TS})\end{array}$ & $D_{1}(\mathrm{~mm})$ & $D_{0}(\mathrm{~mm})$ & $L_{h x}(\mathrm{~mm})$ & $L_{d p}(\mathrm{~mm})$ & $D_{h}(\mathrm{~mm})$ & $a[-]$ & $L_{h x} / D_{h}$ & $L_{d p} / D_{h}$ \\
$(-)$ & $(-)$ & & & & & & \\
\hline 1 & 12.7 & 38.88 & 5060 & 5040 & 26.2 & 0.327 & 193 & 2193 \\
\hline 2 & 15.9 & 38.88 & 5060 & 5040 & 23.0 & 0.409 & 220 & 250 \\
\hline 3 & 12.7 & 32.9 & 5080 & 5060 & 20.2 & 0.386 & 251 & 298 \\
\hline 4 & 15.9 & 32.9 & 5080 & 5060 & 17.0 & 0.483 & 299 & 293 \\
\hline
\end{tabular}

The pressure drop length $\left(L_{p d}\right)$ between the two pressure taps (shown in Figure 2a) was either $5.04 \mathrm{~m}$ or $5.06 \mathrm{~m}$. This resulted in length-to-diameter ratios $\left(L_{p d} / D_{h}\right)$ ranging from 193.1 to 297.65. The pressure taps had inner diameters of $1 \mathrm{~mm}$ and were positioned at the top of the annular passages in the stagnant flow regions, one before the inlet and the other after the outlet. The diameters of the taps were far smaller than the recommended $10 \%$ of the hydraulic diameters of the annuli [35] to avoid significant influence on the pressure readings. Special care was taken to ensure that no burrs were left behind after drilling the holes, and that the tubes were smooth on the inside. A $2.2 \mathrm{kPa}$ pressure transducer with a measurement uncertainty of $\pm 0.0055 \mathrm{kPa}$ (item PT in Figure 1) was used to measure the pressure drop.

Since the lower and upper Reynolds number limits of the transitional flow regime could be affected by the inlet geometry [7, 36, 37], two inlet configurations were considered in this 
study. These were selected to resemble possible upstream configurations commonly found in industrial applications. Many other configurations exist, but only two were considered to determine the sensitivity of the experimental results to the inlet configuration. Both configurations were those of a commercial $90^{\circ}$ T-section fitting preceded by a $90^{\circ}$ elbow with the same diameter as the outer tube of the annular passage. For the first inlet geometry, shown in Figure 2a, the T-section and elbow combination was preceded by an isothermal inlet length, which was directly above the tube-in-tube heat exchanger test section and which ran parallel to the annulus. For this inlet type, the water approached the setup in an opposite flow direction to that in the annulus. The inlet length was long enough to ensure fully hydrodynamic development before the elbow. For the second inlet geometry, shown in Figure $2 \mathrm{~b}$, the inlet length was only $100 \mathrm{~mm}$ and was positioned below the test section. In contrast, the flow in this inlet length approached the test section in the same flow direction as the flow in the annulus. Due to its short length, the flow was still hydrodynamically developing before the elbow.

As will be shown later in this paper, it was found that the inlet configurations had relatively little impact on the experimental results in this investigation, and thus, most of the results presented in this paper are for the first inlet geometry. Despite the fact that the inlet geometry did not appear to affect the transition characteristics, it was ensured that the inlet geometries and their dimensions which depended on the outer tube diameter of the annulus, were proportionally the same. The inlet length was clamped to the outer tube of the heat exchanger by three wooden supports to ensure a fixed relative position between the test section passage and itself. Since two outer tubes of different diameters were used in the assembly of the four test sections, their inlets were geometrically proportional to each other to ensure consistency of inlet conditions. The inlet for a test section consisted of an outer tube with an inner 
diameter of $32.9 \mathrm{~mm}$ and length of $4.2 \mathrm{~m}$, while the elbow had a mid-pipe radius of $25 \mathrm{~mm}$. The centre line distance between the inlet length and the inner tube was $210 \mathrm{~mm}$. While the inlet length for an outer tube with an inner diameter of $38.88 \mathrm{~mm}$ was $5 \mathrm{~m}$, the connecting elbow had a mid-pipe radius of $30 \mathrm{~mm}$. The centre line distance between the inlet length and the inner tube was $248 \mathrm{~mm}$.

To ensure concentricity of the annular passages, the inner tubes were supported by hypodermic needles $(0.8 \mathrm{~mm}$ in diameter $)$ at eight evenly spaced axial positions. Each support position had four needles spaced $90^{\circ}$ apart circumferentially, and was held in place on the outer annular wall in thick-walled acrylic glass connectors. Each outer tube was therefore an assembly of nine copper sections linked to each other via the carefully manufactured acrylic glass connectors, so that the outer wall of each annular passage was smooth and straight.

The inlet and outlet fluid temperatures for the inner tubes were measured at isothermal measuring stations, each consisting of a short copper tube length equipped with four thermocouples connected $90^{\circ}$ apart. These copper lengths were thermally isolated from the test section by means of rubber hoses before and after the measuring stations. The inlet and outlet temperatures of the annular passage fluid were measured in a similar manner as for the inner tube, except that each measuring station was equipped with eight thermocouples. By using several thermocouples at each measuring station, the effective uncertainty based on the arithmetic average was reduced (more information is provided in Section 4). Since very low flow rates were applied in the annulus, which could result in the formation of thick thermal boundary layers, an in-line spiral-type mixer was placed before the outlet temperature measuring station. This was done to disturb the thermal boundary layer and to ensure that the average water temperature was captured accurately. The mixer was made of four copper 
elements of alternating right and left-hand $180^{\circ}$ helices inserted in a copper tube with a diameter of $19.8 \mathrm{~mm}$ and a length of $120 \mathrm{~mm}$.

In order to measure the local inner-wall temperatures, nine evenly spaced measuring stations were manufactured along the length of each inner tube. At each station, two T-type thermocouples were embedded in the wall, one at the top and the other at the bottom. In order to keep the annular passage clear from unnecessary obstructions, the thermocouple leads were passed through the inside of the inner tube. Each thermocouple junction was soldered in a groove $(10 \mathrm{~mm}$ long with a depth of $0.46 \mathrm{~mm}$ ) that was machined into the tube wall. The grooves were filled with solder at the measuring tips and with epoxy in the remainder of the grooves (facing downstream), so that the outer surface of the tube remained smooth. The inlet and outlet ends of the inner tube provided exit ports for these thermocouple leads.

To measure the local outer-wall temperature profiles along the length of each annular passage, sets of two thermocouples each were attached to the outer surface of the outer tube wall at intervals exactly midway between the inner-tube measuring stations. One thermocouple was placed on top and the other at the bottom.

The test sections and all inlet and outlet measuring stations were thermally insulated by covering them with $50 \mathrm{~mm}$-thick elastomeric foam sheets with a thermal conductivity of $0.036 \mathrm{~W} / \mathrm{mK}$ at $23{ }^{\circ} \mathrm{C}$

A computerised data-acquisition system was used to gather the data from the respective measuring instruments. The system consisted of a personal computer using LabVIEW software with which the measurements could be logged and the experimental system 
controlled. The data-acquisition package that was used contained the necessary multiplexers, analogue-to-digital converters and terminal blocks to successfully log the data onto the computer.

\section{Experimental procedure}

Before testing commenced, thermocouples and pressure transducers were checked for accuracy. Thermocouples were calibrated by running steady-state isothermal experiments on each test section by circulating water through the inner tube and annular passage at temperature states ranging from $17{ }^{\circ} \mathrm{C}$ to $55{ }^{\circ} \mathrm{C}$ for long periods of time. Since the inner tube and annular passage were at the same temperature, there was no internal heat transfer. Thermocouple readings were compared against the in situ reading obtained from two PT100 probes, installed at the inlet and outlet of the inner tube and the annulus. The calibration results indicated that the thermocouple measurements were accurate in absolute terms to within a $0.1{ }^{\circ} \mathrm{C}$ band, based on the average PT100 readings. The $2.2 \mathrm{kPa}$ pressure transducer was calibrated using a water column and a manometer with an accuracy of $0.0055 \mathrm{kPa}$. Calibration curves were created with measured data conditioned during the data-processing stages.

During the main experiments, a range of pressure drop and heat transfer tests were conducted on each of the test sections with reference to the fluid in the annulus. In all cases, the water in the inner tube and in the annular passage flowed in opposite directions. Pressure drop tests were done for isothermal adiabatic and diabatic cases, while heat transfer tests were, by definition, only considered for diabatic cases. Isothermal adiabatic pressure drop tests were used as reference cases. During heated annulus cases, heat was transferred from the inner tube (hot water entering at approximately $50{ }^{\circ} \mathrm{C}$ ) to the annular fluid (cold water entering at 
approximately $20^{\circ} \mathrm{C}$ ), while the opposite was true during cooled annulus cases. Isothermal tests were conducted at approximately $19^{\circ} \mathrm{C}$.

As mentioned, an approximate uniform wall temperature condition on the inner walls of the annuli was used in this paper, while the outer walls were adiabatic. A thermal boundary condition on the inner wall was achieved by using high water mass flow rates in the inner tube so that the temperature differences between the fluid in the inlet and outlet of the inner tube were relatively small. In order to quantify the uniformity of the inner wall temperature, the following wall temperature ratio is defined for heated $\left(\tau_{h a}\right)$ and cooled $\left(\tau_{c a}\right)$ cases:

$$
\begin{gathered}
\tau_{h a}=\frac{\bar{T}_{i w, \text { out }}}{\bar{T}_{i w, \text { in }}} \text { (for a heated annulus) } \\
\tau_{c a}=\frac{\bar{T}_{i w, \text { in }}}{\bar{T}_{i w, \text { out }}} \text { (for a cooled annulus) }
\end{gathered}
$$

This is the ratio of the inner wall temperatures (values in degrees Kelvin) at the inlet and outlet of the heat exchanger test section. The ratio has a value smaller or equal to 1 , with a value of 1 representing a perfect uniform wall temperature condition. For a given inlet temperature state, the value of $\tau$ is directly influenced by the relative mass flow rates in the annulus and in the inner tube. By increasing or decreasing the inner tube mass flow rate, depending on the desired annular flow rate, $\tau=0.99 \pm 0.005$ was maintained for all data presented in this paper, which translated to a mean temperature difference between the inlet and outlet of the inner tube of approximately $2{ }^{\circ} \mathrm{C}$. This $(\tau=0.99)$, being within $1 \%$ of $\tau=1$, was treated as being an approximately uniform wall temperature condition. Since the inner wall temperatures at the inlet and outlet were not directly measured, line-fit extrapolations from the measured wall temperature profiles were used. Practically, the maximum achievable water flow rates were restricted by the limitations of the lab facility and the structural 
integrity of the test sections. True uniform wall temperature conditions can only be considered when using condensing or evaporating fluids in the inner tube. This was beyond the capabilities of the experimental facility.

The data was logged upon reaching a steady-state condition when the change in the average annular fluid outlet temperature changed by less than $0.1^{\circ} \mathrm{C}$ over a period of one minute. Up to 120 data points were captured at $10 \mathrm{~Hz}$ for each test data point, which were averaged to produce one data point during the data-reduction stages.

\section{Data reduction}

The heat transfer rates in the inner tube and the annular passage were determined as in equations (2) and (3), respectively:

$$
\begin{gathered}
\dot{Q}_{i}=\dot{m}_{i} c_{p, i}\left(T_{i n, i}-T_{o u t, i}\right) \\
\dot{Q}_{o}=\dot{m}_{o} c_{p, o}\left(T_{i n, o}-T_{\text {out }, o}\right)
\end{gathered}
$$

In both of these equations, the mass flow rates were the measured mass flow rates via the Coriolis mass flow meters of the water through the inner tube and the annular passages. The average inlet and outlet temperatures of the water were obtained from the wall temperature measurements at the inlet and outlet measuring stations. The specific heat values were obtained from the method of Popiel and Wojtkowiak [38] at the average temperature of each stream. The average temperature for the inner tube was determined by the arithmetic average between the measured inlet and outlet fluid temperatures. The average fluid temperature in the annulus was obtained as:

$$
\bar{T}_{b, 0} \cong \frac{1}{L_{h x}} \int_{x_{i n}}^{x_{o u t}} \bar{T}_{o w}(x) d x
$$


where $\bar{T}_{o w}(x)$ is a polynomial fit representing the outer tube wall temperature measurement profile. Equation (4) was used for the annulus, because unlike the inner tube, the annular passage axial bulk fluid temperature profile was not linear - especially at low Reynolds numbers. Thus, by using the arithmetic average between the measured inlet and outlet of the annulus, average fluid temperatures would often have been inaccurately estimated. Therefore, for improved accuracy of the calculated fluid properties, the axial direction fluid temperature profile and the measured outer wall temperature profiles were taken to be approximately the same, which allowed for the determination of a more representative effective average annular fluid temperature for each test condition. All the water properties for the annulus were also determined using this average temperature and relevant equations from Popiel and Wojtkowiak [38].

The energy balance error $(E B)$ was calculated in terms of the average heat transfer rate, $\bar{Q}$ as:

$$
E B=\frac{\dot{Q}_{o}-\bar{Q}}{\bar{Q}},
$$

where

$$
\bar{Q}=\frac{\dot{Q}_{i}+\dot{Q}_{o}}{2}
$$

The logarithmic mean temperature difference (LMTD) method was used to calculate the mean annular heat transfer coefficients based on the averaged inlet and outlet temperatures of the inner tube wall and the annular fluid. As such, the mean annulus heat transfer coefficient, $\bar{h}_{o}$ was defined from Newton's law of cooling as:

$$
\bar{h}=\frac{\dot{Q}_{o}}{A_{s} \Delta T_{L M T D}},
$$

where $A_{\mathrm{s}}$ is the wetted inner annulus surface area, defined as: 


$$
A_{s}=\pi L_{h x} D_{1} .
$$

Since the heat transfer rate calculated from the annulus side data has a lower experimental uncertainty associated with it (also see the end of Section 4), $\dot{Q}_{o}$ was used here. The logarithmic mean temperature difference, $\Delta T_{L M T D}$ for the annular flow passage, was obtained using the relevant arithmetic averages from the calibrated thermocouple measurements and line extrapolations mentioned earlier:

$$
T_{L M T D}=\frac{\left(\bar{T}_{\text {out }, i w}-\bar{T}_{\text {in,o }}\right)-\left(\bar{T}_{\text {in,iw }}-\bar{T}_{\text {outo }}\right)}{\ln \left[\left(\bar{T}_{\text {out }, i w}-\bar{T}_{\text {in }, o}\right) /\left(\bar{T}_{\text {in }, i w}-\bar{T}_{\text {out }, o}\right)\right]}
$$

Even though the approximate axial annular fluid temperature was monitored with the thermocouple measurements on the outer annular wall (as mentioned earlier), the developing nature of the flow did not allow for the exact calculation of local fluid temperatures along the heat exchanger length. Therefore, in this paper, only averaged heat transfer coefficients are presented and not local heat transfer coefficients.

The mean Nusselt number for the annular passage was based on the hydraulic diameter and calculated as:

$$
N u=h D_{h} / k,
$$

where $k$ is the thermal conductivity of the annular fluid.

The Reynolds number for flow in the annular passage was calculated as: 


$$
\operatorname{Re}=\frac{\dot{m}_{o} D_{h}}{\mu_{o} A_{o}}=\frac{4 \dot{m}_{o}}{\pi \mu_{o}\left(D_{0}+D_{1}\right)}
$$

The Richardson number, which indicates the importance of natural convection relative to the forced convection, was calculated as:

$$
\mathrm{Ri}=\frac{\mathrm{Gr}}{\mathrm{Re}^{2}}
$$

The Grashof number was calculated as:

$$
\mathrm{Gr}=\frac{g \beta\left(T_{i w}-T_{b, o}\right) D_{h}^{3}}{v^{2}}
$$

In eq. (13), $g$ is acceleration due to gravity, $v$ is kinematic viscosity $(\mu / \rho)$ and $\beta$ is the volumetric expansion coefficient.

The average friction factors at different Reynolds numbers were determined from the measured pressure drop, $\Delta p$, over the distance between the two pressure taps, as:

$$
f=\frac{2 D_{h} \Delta p}{\rho_{o} L_{p d} V_{o}^{2}}
$$

The velocity of the water in the annulus was determined from the measured mass flow rate in the annulus, and the cross-sectional annulus area and average fluid density at the bulk temperature.

$$
V_{o}=\frac{\dot{m}_{o}}{\left(\rho_{o} A_{o}\right)}
$$


An uncertainty analysis of the overall experimental procedures, focusing on the annular passage, based on the method of Moffat [39], was performed. For convenience, the relevant uncertainties of the measuring instruments on the test facility are summarised in Table 2 . The uncertainties at lower and upper Reynolds number limits (discussed in Section 6) of the transitional flow regime of mean Nusselt numbers and friction factors for the heated and cooled annulus cases are presented in Table 3. For all the test sections, higher Nusselt number uncertainties occurred at low Reynolds numbers. These uncertainties were observed to decrease with increasing Reynolds numbers. Even though the resulting smaller temperature differences associated with higher flow rates tend to increase heat transfer uncertainty values, the lower uncertainties of flow meter readings at high flow rates resulted in an overall reduction in the Nusselt number uncertainty. For friction factors, higher uncertainties were observed at low Reynolds numbers due to higher uncertainties associated with the pressure transducer measurements at lower flow rates. As the Reynolds number was increased, thus reducing uncertainties in the pressure drop measurement, the friction factor uncertainties were also reduced. Generally, it is observed for both Nusselt numbers and friction factors that the lowest uncertainties were for the largest hydraulic diameter of $26.2 \mathrm{~mm}$ (TS 1) and that the uncertainties increased when decreasing the hydraulic diameter.

Table 2: $\quad$ Applicable experimental measuring ranges and associated uncertainties

\begin{tabular}{|l|l|l|}
\hline & \multicolumn{1}{|c|}{ Range } & \\
\hline T-type thermocouples & $-200-350{ }^{\circ} \mathrm{C}$ & $\pm 0.106^{\circ} \mathrm{C}$ \\
\hline Flow meters & $0-0.604 \mathrm{~kg} / \mathrm{s}$ & $\pm 0.1 \%$ \\
& $0.3-1.4 \mathrm{~kg} / \mathrm{s}$ & $\pm 0.1 \%$ \\
\hline Differential pressure transducer & $0-2.2 \mathrm{kPa}$ & $\pm 0.0055 \mathrm{kPa}$ \\
\hline
\end{tabular}


Table 3: $\quad$ Uncertainties expressed as percentage for Nusselt number and friction factor from the lower to upper Reynolds number limits of the transitional regime

\begin{tabular}{|c|c|c|c|c|c|}
\hline \multirow{2}{*}{$\begin{array}{c}\text { Test } \\
\text { section } \\
(\mathrm{TS})\end{array}$} & \multirow{2}{*}{$\begin{array}{c}D_{h} \\
(\mathrm{~mm})\end{array}$} & \multicolumn{2}{|c|}{ Nusselt number } & \multicolumn{2}{|c|}{ Friction factor } \\
\hline & & $\begin{array}{c}\text { Heated } \\
\text { annulus (\%) }\end{array}$ & $\begin{array}{c}\text { Cooled annulus } \\
(\%)\end{array}$ & $\begin{array}{c}\text { Heated annulus } \\
(\%)\end{array}$ & $\begin{array}{c}\text { Cooled annulus } \\
(\%)\end{array}$ \\
\hline 1 & 26.2 & $6.56-1.21$ & $6.90-1.32$ & $3.16-1.07$ & $3.42-1.08$ \\
\hline 2 & 23.0 & $7.00-1.20$ & $7.01-1.33$ & $3.81-1.22$ & $3.47-1.21$ \\
\hline 3 & 20.2 & $8.97-1.38$ & $8.33-1.60$ & $5.22-1.48$ & $4.17-1.45$ \\
\hline 4 & 17.0 & $9.32-1.50$ & $8.79-1.74$ & $5.52-1.65$ & $4.31-1.49$ \\
\hline
\end{tabular}

\section{Validation and comparison}

Little to no correlations were available in the literature that could be used to validate the transitional flow regime results. Therefore, validation of the test method was only performed in the turbulent regime. The equstion of Filonenko [40] which was modified for application in annular passages by Gnielinski [41], Equation (16), was used to validate the friction factors, as shown in Figure 3(a).

$$
f_{o}=\left(1.8 \log _{10} \operatorname{Re}^{*}-1.5\right)^{-2}
$$

where

$$
\operatorname{Re}^{*}=\operatorname{Re}_{D h} \frac{\left(1+a^{2}\right) \ln a+\left(1-a^{2}\right)}{(1-a)^{2} \ln a}
$$

The data presented in the figure is for the test sets of TS 4 . The figure displays data for the laminar, transitional and turbulent flow regimes. The Reynolds number limits between the flow regimes will be discussed in Section 6.2. In Figure 3a, containing the isothermal adiabatic friction factors, it is observed that the experimentally obtained mean friction factors were higher than those predicted by Equation 16. This is due to the influence of the hydrodynamic entrance region when the flow is developing. In the hydrodynamic entrance region, the wall shear stress is highest at the pipe inlet where the boundary layer thickness is 
the smallest, and decreases along the flow direction. Therefore, the pressure drop is the highest in the entrance region of a flow duct. Hence, it always increases the mean friction factor for the whole flow duct. Equation 16 under-predicted the mean experimental friction factors by 10\%, 12\%, 18\% and 23\% for test sections TS 1, TS 2, TS 3 and TS 4 respectively.
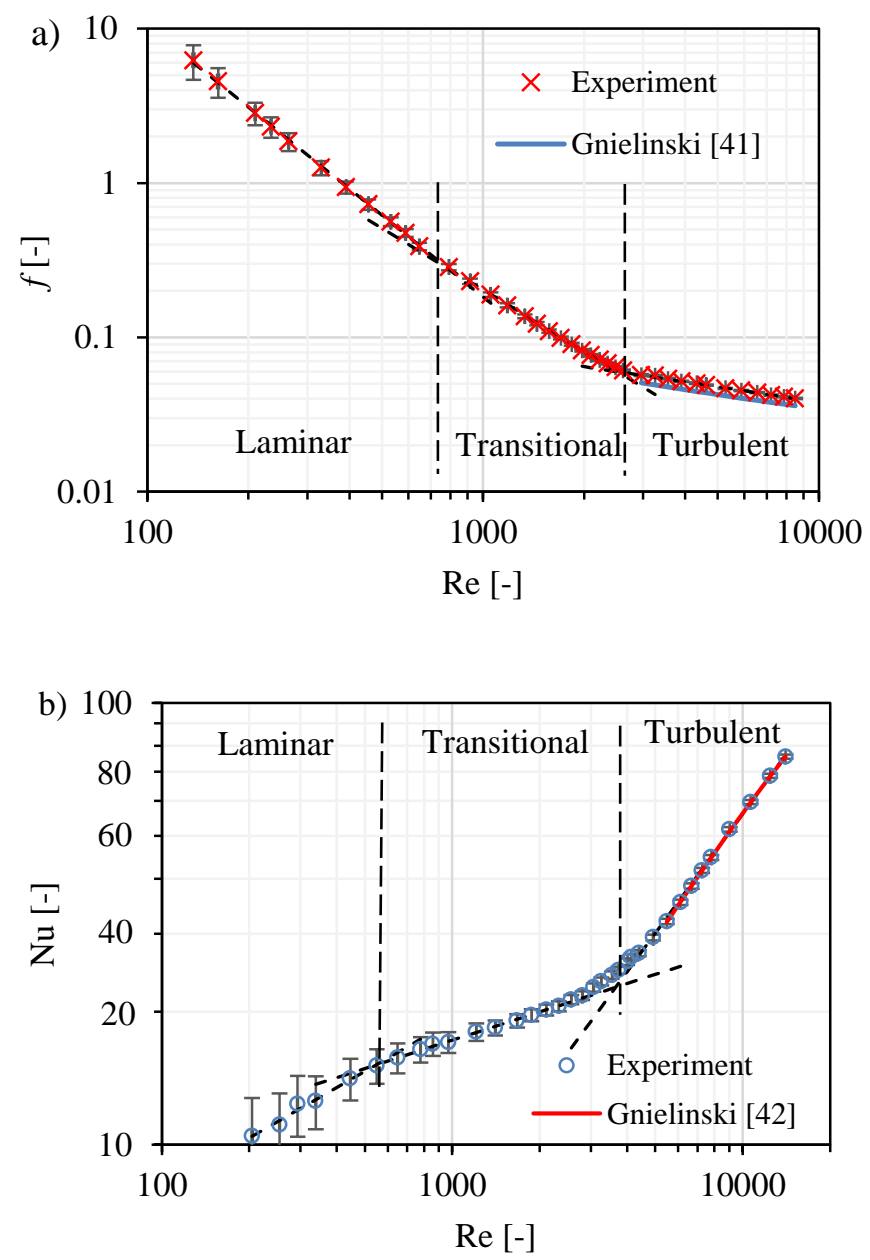

Figure 3: $\quad$ Comparison of: (a) isothermal friction factor results; and (b) heat transfer results for a heated annulus case with literature references

The heat transfer results were also compared to the turbulent flow correlation of Gnielinski [42], given in equation (18) in Figure $3 \mathrm{~b}$. As mentioned in the experimental procedure, the limitations of the lab facility and the structural integrity of the test sections resulted in only a few data points in the turbulent regime of the heated annulus case; therefore, only the cooled annulus cases have been used for validation purposes. 


$$
N u=\frac{\left(f_{o} / 8\right)(\operatorname{Re}-1000) \operatorname{Pr}}{1+12.7 \sqrt{\left(f_{o} / 8\right)}\left(\operatorname{Pr}^{2 / 3}-1\right)}\left[1+\left(\frac{D_{h}}{L}\right)^{2 / 3}\right] F_{o} K
$$

where

$$
F_{o}=0.75 a^{-0.17}, K=\left(\frac{\operatorname{Pr}_{b}}{\operatorname{Pr}_{w}}\right)^{0.11} \text { and } f_{o} \text { as in Equation } 16
$$

Equation 18 was found to slightly under-predict the experimental results for test section TS 1 , Figure $3 \mathrm{~b}$, by $0.8 \%$. The data for the other test sections, TS 2, TS 3 and TS 4 , were underpredicted by $1.0 \%, 1.2 \%$ and $1.6 \%$ respectively. Uncertainty bars are included in Figure 3, based on the uncertainty propagation analyses.

\section{Results and discussions}

The effect of the inlet geometry on the lower and upper Reynolds number limits of the transitional flow regime was investigated prior to the main investigation. Therefore, its results are presented first, followed by the mean heat transfer coefficient and friction factor, and the transitional flow regime characteristics. The effects of the geometrical sizes of the annular passages and heat transfer direction on the heat transfer coefficient, friction factor and transitional flow ranges are discussed later in this section.

\subsection{Inlet configuration}

Isothermal experiments were conducted to investigate the effect of the inlet configuration on the lower and upper Reynolds number limits of the transitional flow regime based on the firction factor. The two inlet configurations (Figure 2), as described in Section 2, were considered. Figure 4 gives the mean friction factor results for the two inlet configurations. From this figure it follows that the results were very similar, therefore the transitional flow 
regime results in this article are repeatable in terms of the impact of the inlet geometry used in this investigation.

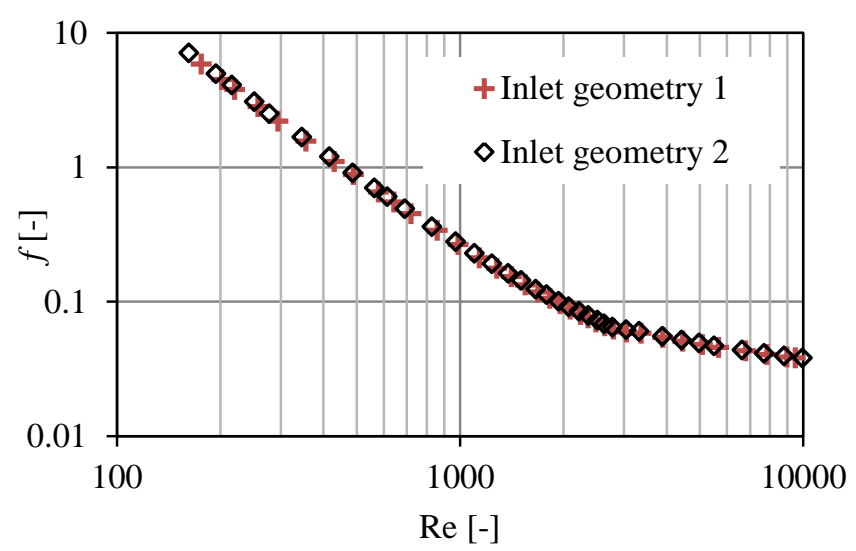

Figure 4: $\quad$ Friction factor results for inlet geometries 1 and 2

\subsection{Transitional flow regime Reynolds number limits}

Test data encompassing laminar, transitional and turbulent regimes were analysed to get the lower and upper limits of the transitional flow regimes for the different test sections. For this purpose, the lengthwise averaged friction factors and Nusselt numbers were plotted against the Reynolds number (both on a logarithmic scale) for all the test cases and carefully analysed to identify changes in the characteristic gradients of the plots. Both the plots exhibited distinct sections that are approximately linear in nature with different gradients for laminar, transitional and turbulent regime ranges. Therefore, by using a root mean square deviation method, straight lines were generated which were used to trace out the regimes. This is illustrated with dashed lines in Figure 3 . The mid-range region, as defined by the intersections of the three lines, indicates the transitional flow regime, while the low and high Reynolds number ranges indicate the laminar and turbulent regimes, respectively. The lower and upper Reynolds number limits of the transitional flow regimes $\left(\operatorname{Re}_{1}\right.$ and $\operatorname{Re}_{2}$, respectively) are presented in Table 4 for all the test sections. Here, $\operatorname{Re}_{1}$ refers to the 
Reynolds number limit between the laminar flow regime and the transitional flow regime, while $\mathrm{Re}_{2}$ refers to the limit between the transitional flow regime and the turbulent flow regime. The column that indicates the percentage of data points in the transitional flow regime that are mixed convection cases will be discussed shortly. For convenience, the transitional flow regime ranges in terms of the Reynolds number are represented graphically in Figure 5(a) and Figure 5(b) based on the heat transfer coefficient and friction factor respectively.

Table 4: $\quad$ Heat transfer and flow transition ranges for isothermal, heated and cooled annuli based on Reynolds numbers, and mixed convection size also based on Reynolds numbers

\begin{tabular}{|c|c|c|c|c|c|c|}
\hline \multirow[b]{2}{*}{ TS } & \multicolumn{3}{|c|}{ Transition based on Nusselt number } & \multicolumn{3}{|c|}{ Transition based on friction factor } \\
\hline & $\operatorname{Re}_{1}$ & $\mathrm{Re}_{2}$ & $\begin{array}{c}\text { Percentage of } \\
\text { transitional flow regime } \\
\text { data points that are } \\
\text { mixed convection cases }\end{array}$ & $\mathrm{Re}_{1}$ & $\mathrm{Re}_{2}$ & $\begin{array}{l}\text { Percentage of } \\
\text { transitional flow } \\
\text { regime data points } \\
\text { that are mixed } \\
\text { convection cases }\end{array}$ \\
\hline & \multicolumn{6}{|c|}{ Heated annulus cases } \\
\hline 1 & 790 & 4900 & $70 \%$ & 1410 & 4170 & $89 \%$ \\
\hline 2 & 600 & 4170 & $67 \%$ & 1200 & 3160 & $82 \%$ \\
\hline 3 & 550 & 3990 & $55 \%$ & 1100 & 3090 & $67 \%$ \\
\hline \multirow[t]{2}{*}{4} & 490 & 3470 & $50 \%$ & 1000 & 2820 & $58 \%$ \\
\hline & \multicolumn{6}{|c|}{ Cooled annulus cases } \\
\hline 1 & 660 & 6320 & $100 \%$ & 1520 & 5890 & $100 \%$ \\
\hline 2 & 590 & 5260 & $100 \%$ & 1250 & 4910 & $100 \%$ \\
\hline 3 & 500 & 5020 & $98 \%$ & 1230 & 4800 & $96 \%$ \\
\hline \multirow[t]{2}{*}{4} & 400 & 3980 & $75 \%$ & 1000 & 3980 & $60 \%$ \\
\hline & \multicolumn{6}{|c|}{ Isothermal adiabatic cases } \\
\hline 1 & & & & 890 & 2950 & \\
\hline 2 & & & & 850 & 2710 & \\
\hline 3 & & & & 830 & 2620 & \\
\hline 4 & & & & 800 & 2500 & \\
\hline
\end{tabular}

Unlike in the case for a circular tube, where transition based on the friction factor and the heat transfer coefficient from laminar to turbulent starts and ends concurrently, in annular passages, transition based on the heat transfer coefficient often starts earlier than transition based on the friction factor. This is also the case in this study, and reflects similar observations made by Lu and Wang [24, 25] for a narrow annulus. The difference in the 
transitional range behaviour for the heat transfer coefficient and the friction factor is due to the fact that the friction factor is influenced by both the outer and inner wall surfaces, while the heat was only transferred at the inner wall surface (the outer wall being isothermal).
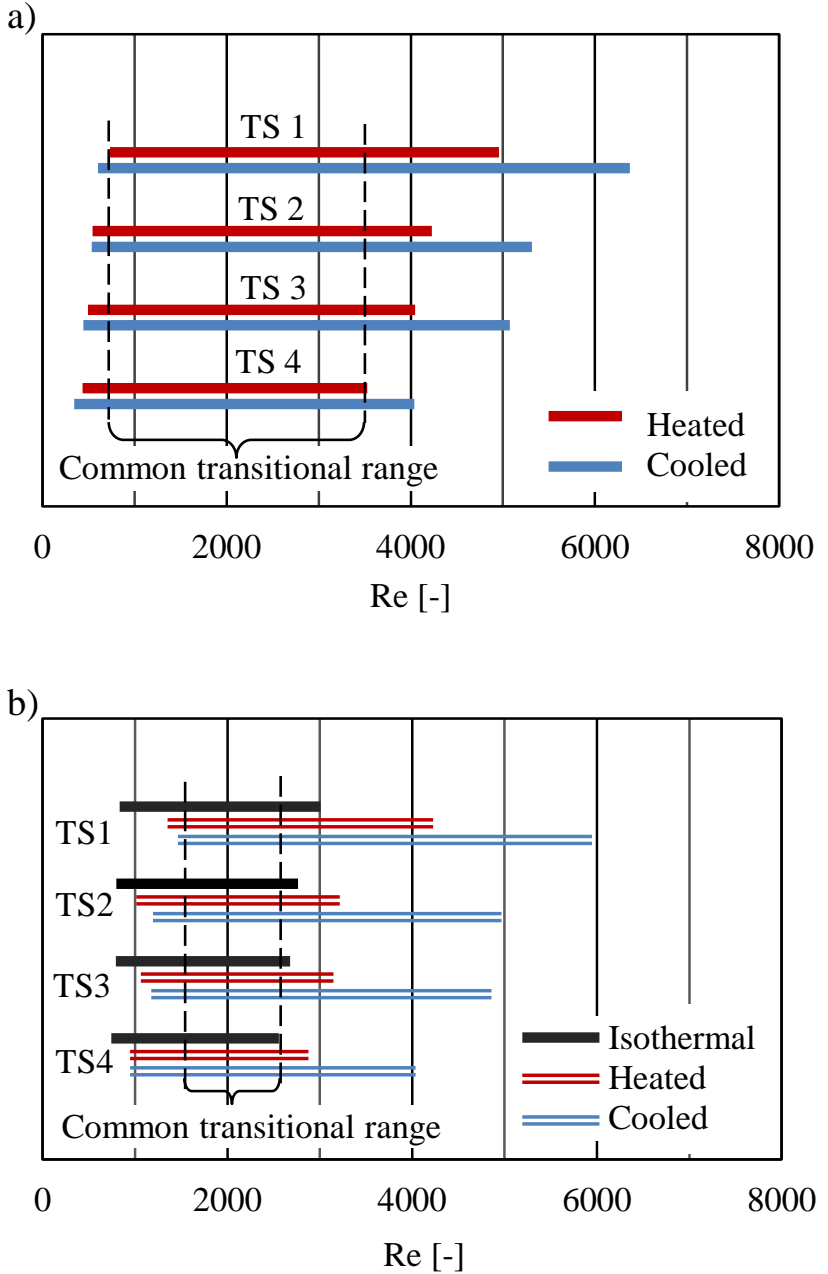

Figure 5: $\quad$ A graphical representation of transition ranges for: (a) heat transfer; and

(b) friction factor

\subsection{Buoyancy-driven secondary flow}

In order to better interpret the observed $\mathrm{Re}_{1}$ and $\mathrm{Re}_{2}$ trends, as well as the results that will follow, the impact of the convection types (natural, mixed and forced), as indicated by the Richardson number, must be considered. The boundaries between the different convection types are determined by the Richardson number, given in equation (12). Mixed convection 
conditions are considered when $0.1 \leq \mathrm{Ri} \leq 10$. For $\mathrm{Ri}>10$, the flow is treated as natural convection, and the forced convection is considered when $\mathrm{Ri}<0.1$. It was found that, for all the test sections (for both heated and cooled annuli), laminar flow cases exhibited mixed convection, while the turbulent flow cases exhibited forced convection. In most of the tests, the indicative cut-off point $(\mathrm{Ri} \approx 0.1)$ between the mixed and forced convection was found to fall within the transitional flow regimes. Figure 6 depicts the spread of experimental data in the three convection regimes across the Reynolds number span considered during the experimental test sets. Since each test section and test case type had different $\operatorname{Re}_{1}$ and $\operatorname{Re}_{2}$ values (see Table 4), the indicative transitional flow regime ranges shown in Figure 6 are based on the average $\operatorname{Re}_{1}$ and $\mathrm{Re}_{2}$ values and are only included for discussion purposes. It can be observed that the test section with the largest annular gaps (hydraulic diameters) had the highest Richardson number values.

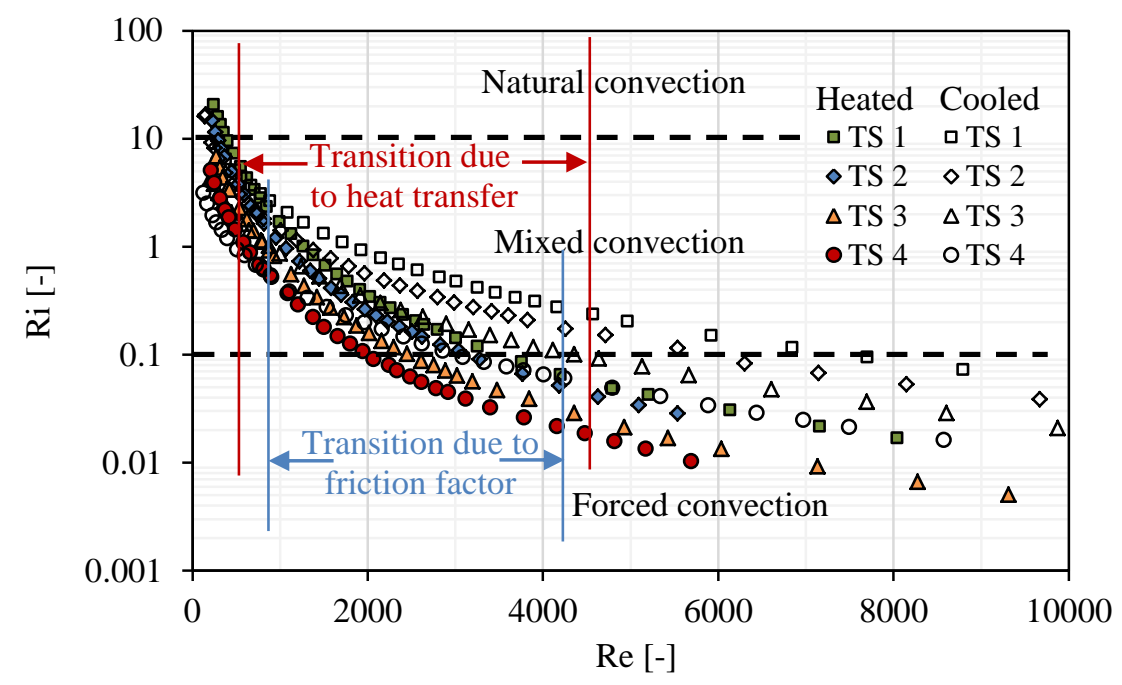

Figure 6: Richardson numbers for heated and cooled annulus cases

The mixed convection portions (expressed as percentages) are higher for the test section with larger hydraulic diameters. As the hydraulic diameter decreases, the Richardson number values and mixed convection portion of the transitional flow regime decrease as well. In 
terms of the heated and cooled annulus cases, the cooled cases also have larger proportions of the mixed convection region. In fact, in TS 1 and TS 2 the entire transitional regime range is in the mixed convection region.

In all the cases considered, the $\operatorname{Re}_{1}$ values (based on either the heat transfer coefficient or the friction factor) were higher for TS 1 , followed by TS 2, TS 3 and TS 4 consecutively. This trend relates linearly to the hydraulic diameters of these test sections. Similarly, $\operatorname{Re}_{2}$ was also higher for the test section with larger hydraulic diameters. The Reynolds number spans of the transitional flow regimes $\left(\operatorname{Re}_{2}-\mathrm{Re}_{1}\right)$ were also found to be related to the hydraulic diameters. Larger hydraulic diameters exhibited longer spans and smaller hydraulic diameters exhibited shorter spans.

It was also observed that the $\operatorname{Re}_{1}$ value based on the friction factor was lowest for the isothermal cases, followed by the heated cases, and finally the cooled cases, which exhibited the largest $\mathrm{Re}_{1}$ values. The $\mathrm{Re}_{2}-\mathrm{Re}_{1}$ ranges for the cooled cases were the longest, followed by the heated cases. For the isothermal cases, these ranges were the shortest.

By considering, for instance, the friction factor data, the differences in the $\operatorname{Re}_{1}$ and $\operatorname{Re}_{2}$ values obtained from the different test sections for isothermal cases could be due to changes in the annular dimensions. In the diabatic cases, apart from the annular dimensions, changes in the friction factors in the transitional flow regime could also be due to temperature variation differences between the annular fluid and the inner wall of the annular passage, as well as the fluid viscosity, which is relatively temperature sensitive. This would have a similar impact on the $\operatorname{Re}_{1}$ and $\mathrm{Re}_{2}$ values based on the heat transfer coefficient. 
As the annular gap size (hydraulic diameter) and/or heat transfer direction changes, the temperature difference between the annular fluid and the inner wall of the annular passage changes as well. Representative temperature difference profiles for the four test sections that were considered are shown in Figure 7 at a Reynolds number value of 2000 for a heated annulus case. A Reynolds number value of 2000 was selected because it falls within the common transition range. Buoyancy-driven flow is expected to be stronger at higher temperature differences between the wall and the bulk fluid, than at lower temperature differences. This could affect the starting and ending points of the transitional flow regime.

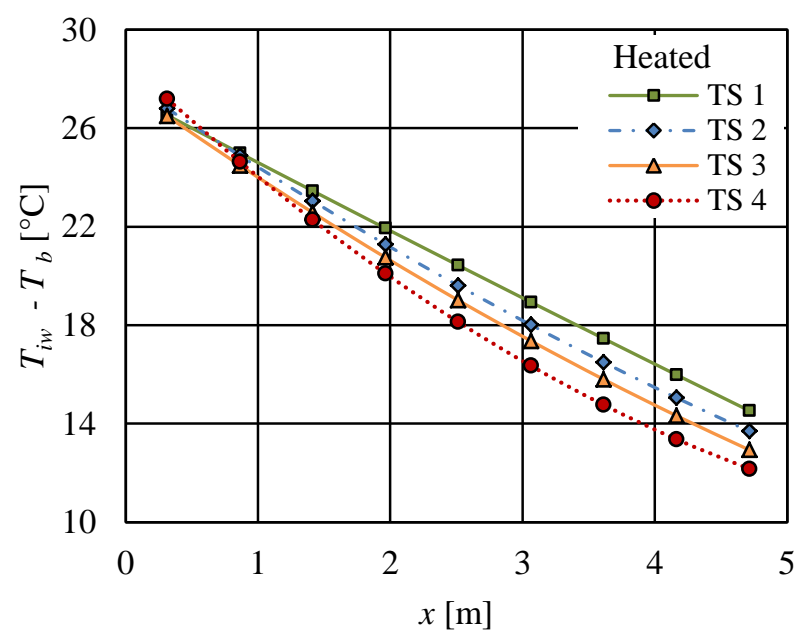

Figure 7: Temperature difference between the inner wall and the bulk fluid for different test sections ar Re $=2000$

\subsection{Mean Nusselt number}

Figure 8 shows the experimental mean Nusselt numbers for all the test sections. The results, which include all regimes from laminar to turbulent, are presented for both heated and cooled cases. In the transitional flow regime, significant differences in Nusselt numbers were observed between the different test sections. TS 1 had the highest Nusselt numbers, followed by TS 2, TS 3 and TS 4. For instance, at a Reynolds number of 2000 , the Nusselt numbers of 
a heated annulus for TS 2, TS 3 and TS 4 were respectively 16\%, 20\% and 37\% lower than for TS 1 . These differences are directly proportional to the hydraulic diameter of the test sections, even though the hydraulic diameter is already included in the definition of the Nusselt number. Similarly, for a cooled annulus case, the Nusselt number values of TS 2, TS 3 and TS 4 were respectively 19\%, 21\% and 35\% lower than for TS 1 . As was observed in Figure 6 in terms of the convection regions, TS 1 had a stronger buoyancy force, which resulted in better fluid mixing and higher Nusselt numbers than the other test sections. This phenomenon decreased with hydraulic diameter size.

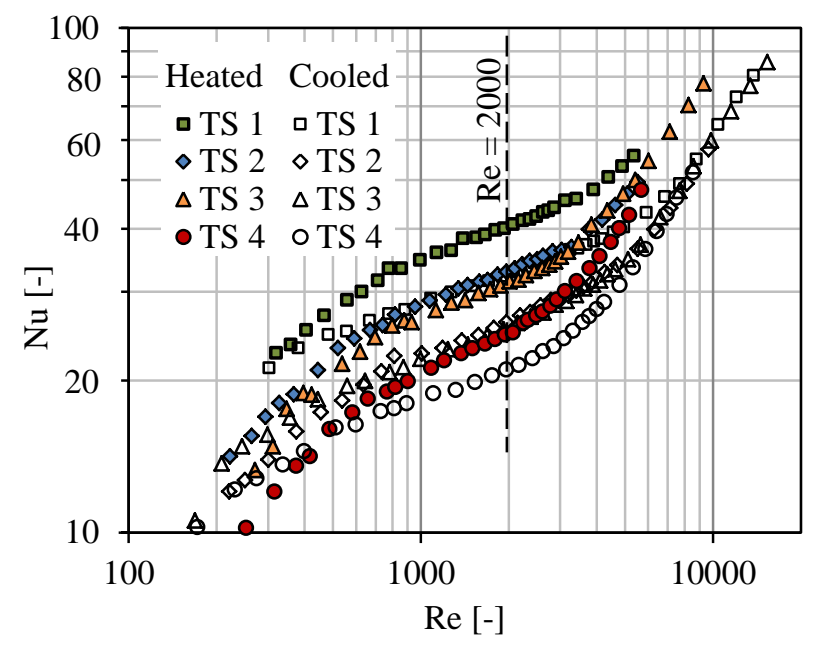

Figure 8: Nusselt numbers for different test sections for heated and cooled annulus cases

A comparison between the heated and cooled annulus cases for the individual test sections shows that, at any given Reynolds number in the transitional flow regime, the Nusselt numbers for the heated annulus were higher than for the cooled annulus. An analysis of Nusselt numbers for TS 1, TS 2, TS 3 and TS 4 at a Reynolds number of 2000 shows that heat transfer coefficients for the heated annulus cases were higher by $21 \%, 25 \%, 23.0 \%$ and $18 \%$ respectively, than they were for the cooled annulus cases. Similar observations were made by Prinsloo et al. [14] and van Zyl et al. [15]. This is caused by the variation of the 
temperature differences between the bulk annular fluid temperature and the inner wall temperature of the annular passage, as well as the fluid Prandtl and Grashof numbers.

\subsection{Mean friction factor}

The friction factors for the isothermal cases for the four heat exchangers are plotted with respect to the Reynolds number in Figure 9(a) while the friction factors for the heated and cooled cases are presented in Figure 9(b). In Figure 9(a), TS 1 has higher friction factors, followed by TS 2, TS 3 and TS 4. In this analysis, friction factors were also found to be more dependent on the hydraulic diameter and increased as the annular gap increased.

A comparison at a Reynolds number of 2000 of the friction factors (isothermal case) for TS 1 against the friction factors for the other test sections shows that TS 2, TS 3 and TS 4 had friction factors that were respectively $26 \%, 31 \%$ and $40 \%$ lower than for TS 1 . When heat transfer is introduced in the flow, as shown in Figure 9b, the friction factors remain higher for TS 1 for both the heated and cooled annulus cases. For the heated case, the friction factors of TS 2, TS 3 and TS 4 at a Reynolds number of 2000 were respectively 40\%, 44\% and 54\% lower than for TS 1. For cooled cases, the friction factors of TS 2, TS 3 and TS 4 were respectively $44 \%, 52 \%$ and $63 \%$ lower than for TS 1 . The friction factors for the cooled cases were higher than for the heated cases in all the test sections. Again, at a Reynolds number of 2000 , the cooled annulus case friction factors for TS 1, TS 2, TS 3 and TS 4 were respectively $72 \%, 60 \%, 48 \%$ and $40 \%$ higher than their counterparts for the heated annulus case. The difference in friction factors between the isothermal and diabatic cases, and also between the cooled and heated annulus cases for a particular test section, could be due to various factors, including the different viscosity values on the inner wall of the annulus, as determined by wall temperature. 

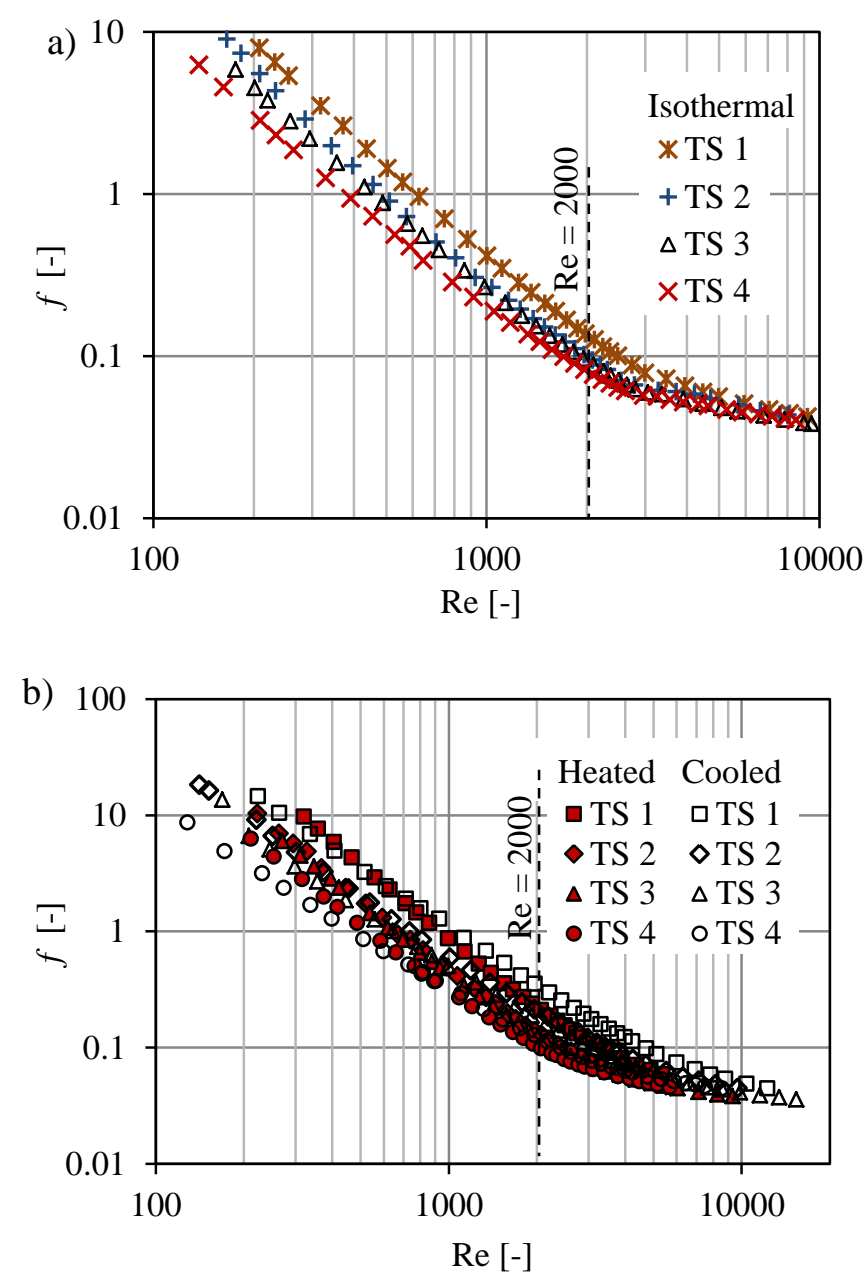

Figure 9: Friction factors for different test sections: (a) for isothermal cases; and (b) for heated and cooled annulus cases

A comparison of the friction factors between cooled and isothermal cases for each test section, also at a Reynolds number of 2000 , shows that the friction factors for cooled cases were higher than for isothermal cases. The friction factors for TS 1, TS 2, TS 3 and TS 4 were respectively $190 \%, 123 \%, 103 \%$ and $82 \%$ higher than their isothermal values. However, the increases in friction factor for forced convection, based on its dependence on the fluid viscosity and radial velocity gradient, $\mu(d v / d r)$ would be approximately $51 \%$ above the isothermal friction factor. As this value is much lower than the increases in the experimental friction factors obtained, it can be concluded that the increase in friction factors is partly due 
to the secondary flow in the annulus. Figure 10 illustrates this phenomenon for the cooled annulus case of TS 1 in the transitional Reynolds number range of 1400 to 2500.

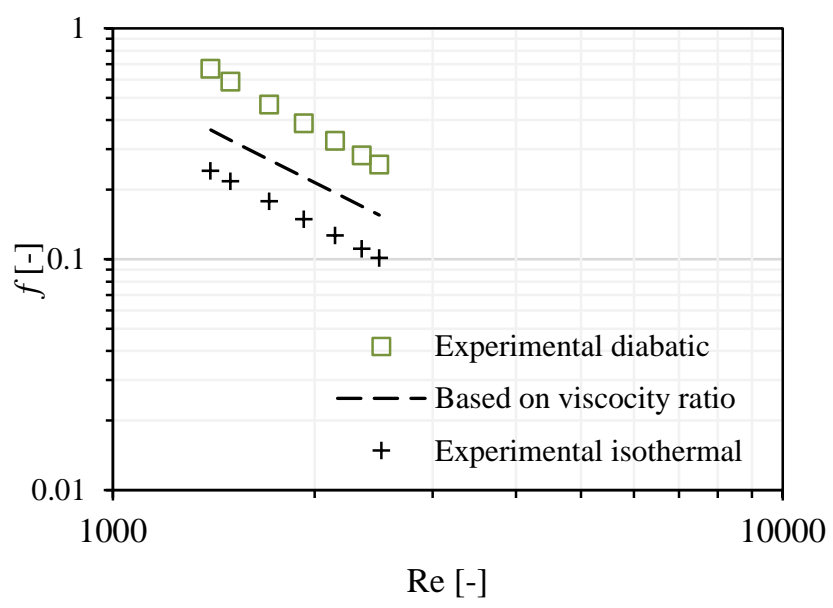

Figure 10: Comparison between friction factor values for diabatic experimental data and forced convection calculated based on viscosity ratio

\section{Proposed correlations}

Correlations for the heat transfer coefficients and friction factors were developed within the common transitional Reynolds number range that covered the experimental data of all the tests. These ranges are illustrated in Figure 5a for transition based on the heat transfer coefficient, and in Figure $5 \mathrm{~b}$ for transition based on the friction factor.

\subsection{Geometric parameter}

From existing correlations for circular tubes and an annulus operated in mixed convection conditions, it is known that the Nusselt number is dependent on the Grashof, Prandtl and Reynolds numbers $[11,22,43]$. Since most of the data points in the transitional flow regime in this investigation were for mixed convection conditions (Figure 6), the following form for the Nusselt number correlation was adopted: 


$$
N u=C \lambda^{-n}
$$

The heat transfer coefficient has some dependence on the annular passage dimensions expressed via a parameter $\lambda$. The coefficient $C$ and exponent $n$ take into account the effects of $\mathrm{GrPr} / \mathrm{Re}$.

To correctly capture the impact of the annular passage dimensions, it was important to identify a suitable mathematical form for $\lambda$. As shown earlier, the characteristics of the transitional Reynolds number spans, heat transfer coefficients and friction factors were significantly dependent on the annular gap size (hydraulic diameter). In addition, several correlations for the annular passage available in literature show that heat transfer and friction factor may also depend on the annular diameter ratio [14, 15, 44-48]. Thus, it is evident that both the annular diameter ratio and the hydraulic diameter have to be considered. In that sense, it is possible to have annular passages that share the same annular diameter ratio, but with different annular gap sizes, and which exhibit different heat transfer coefficient and/or friction factor characteristics. Conversely, different annular passages might share the same hydraulic diameter, but may have different annular diameter ratios.

Furthermore, it is known that the axial length (heat transfer length and pressure drop length) also affects the heat transfer coefficients and friction factors, especially when flow is developing. The length is usually presented in dimensionless form as a length-to-diameter ratio $L / D_{h}$. For instance, Gnielinski [42] considered this ratio in equation (18). As mentioned earlier, and as included in Table 1, the test sections in this paper exhibited different $L / D_{h}$ ratios. Since $L_{h x} / D_{h} \approx L_{d p} / D_{h}$, the values of $L_{h x} / D_{h}=L / D_{h}$ are used in the remainder of this paper. 
Based on the datasets, it was found via inspection that a plausible combined effect of the annular diameter ratio, hydraulic diameter and heat transfer and pressure drop length on the heat transfer coefficients and friction factors could be described in dimensionless form as:

$$
\lambda=\frac{a L}{D_{h}}
$$

An example case of the Nusselt number data dependence on the annular diameter ratio, $a$, and $\lambda$ are shown in Figure 11 at Reynolds numbers of 2000 . It can be observed that the dependence of the Nusselt number on $\lambda$ (Figure 11a) is better defined than on the annular diameter ratio alone (Figure $11 \mathrm{~b}$ ). This $\mathrm{Nu}-\lambda$ trend was evident for all the data points in the transitional flow regime.

A similar behaviour was observed in the isothermal friction factors, $f_{\text {iso }}$. This allowed for isothermal friction factors to be related to the Reynolds numbers using the following form:

$$
f_{\text {iso }}=C_{\text {iso }}(\lambda) \operatorname{Re}^{-m(\lambda)}
$$

The coefficient $C_{i s o}(\lambda)$ and exponent $n(\lambda)$ are dependent on a geometric parameter $\lambda$.

Diabatic friction factors, $f_{d}$, were adjusted from the isothermal friction factors by incorporating the viscosity ratio between the bulk fluid state and the fluid state at the heat transfer wall:

$$
f_{d}=f_{i s o} \lambda^{z} C_{d}\left(\frac{\mu_{b}}{\mu_{i w}}\right)
$$

Coefficient $C_{d}$ and exponent $z$ are dependent on Grashof and Prandtl numbers. 

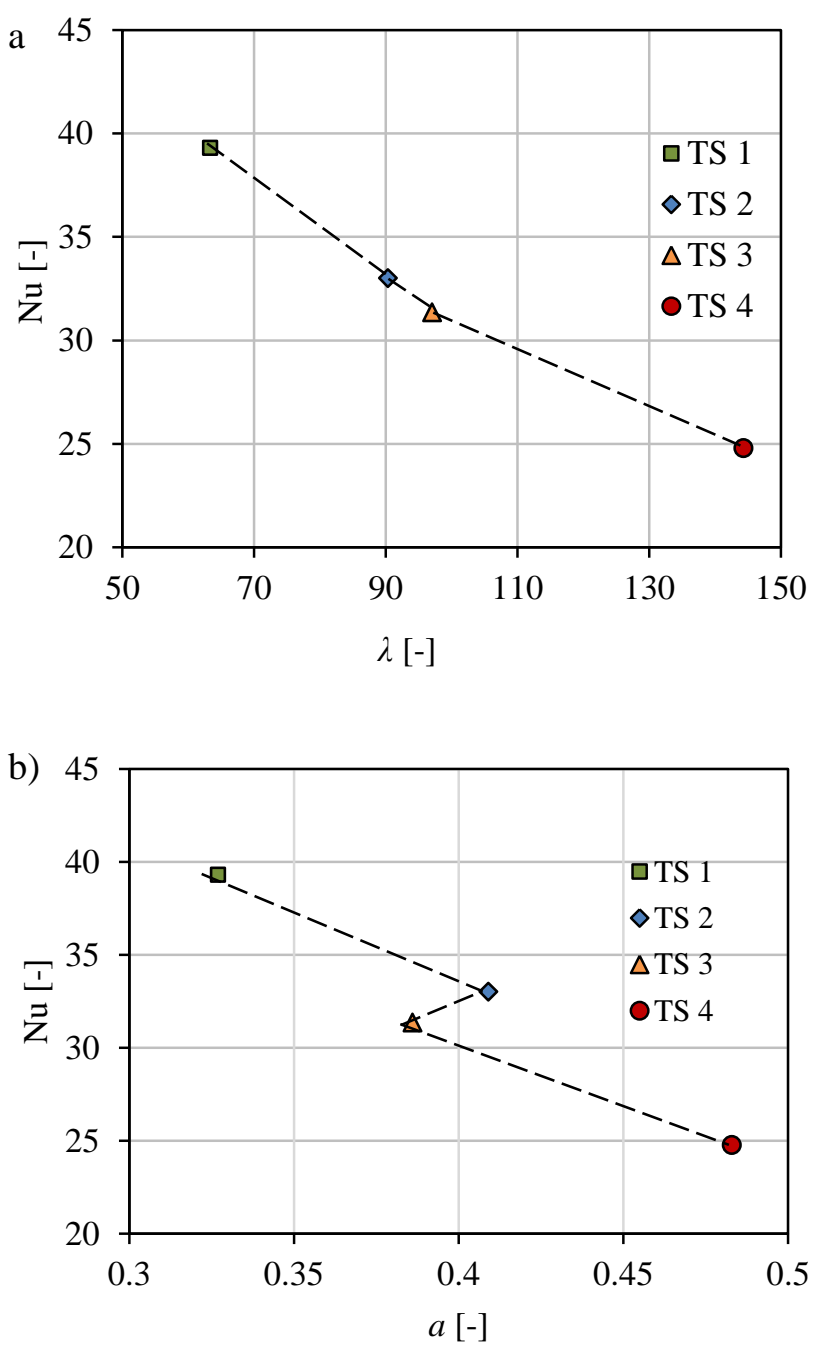

Figure 11: Nusselt number values for $\mathrm{Re}=2000$ plotted against: (a) annular geometric parameter and (b) annular diameter ratio

To complete the construction of the correlations, expressions for $\lambda, C, n, C_{i s o}, m, C_{d}$ and $z$ are needed. This was done iteratively by minimising the root mean square deviation of the predicted Nusselt number and friction factor values compared to the experimentally obtained values.

\subsection{Coefficients and exponents for the Nusselt number correlation}

Expressions for the coefficient and exponent in equation (20) for heated and cooled annulus cases were obtained as: 
For heated annuli:

$$
\begin{aligned}
& C=134\left(\frac{\mathrm{GrPr}}{\mathrm{Re}}\right)^{0.401} \\
& n=0.32\left(\frac{\mathrm{GrPr}}{\mathrm{Re}}\right)^{0.147}
\end{aligned}
$$

For an applicable range of $790 \leq \operatorname{Re} \leq 3490,620 \leq \mathrm{GrPr} / \mathrm{Re} \leq 9700$ and $63 \leq \lambda \leq 145$.

For cooled annuli:

$$
\begin{aligned}
& C=1183\left(\frac{\mathrm{GrPr}}{\mathrm{Re}}\right)^{0.28} \\
& n=0.496\left(\frac{\mathrm{GrPr}}{\mathrm{Re}}\right)^{0.122}
\end{aligned}
$$

For an applicable range of $660 \leq \operatorname{Re} \leq 3980,1000 \leq \mathrm{GrPr} / \mathrm{Re} \leq 12000$ and $63 \leq \lambda \leq 145$

The mathematical formulation of these coefficients and exponents was purposefully selected to match the formulation in Equation (20).

Figure 12 shows the comparison between the experimental and predicted Nusselt number for the heated and cooled annulus cases. The agreement between the experimental results and the proposed correlations was good, with all the data points within a $\pm 8 \%$ error band for both the heated and cooled cases. 


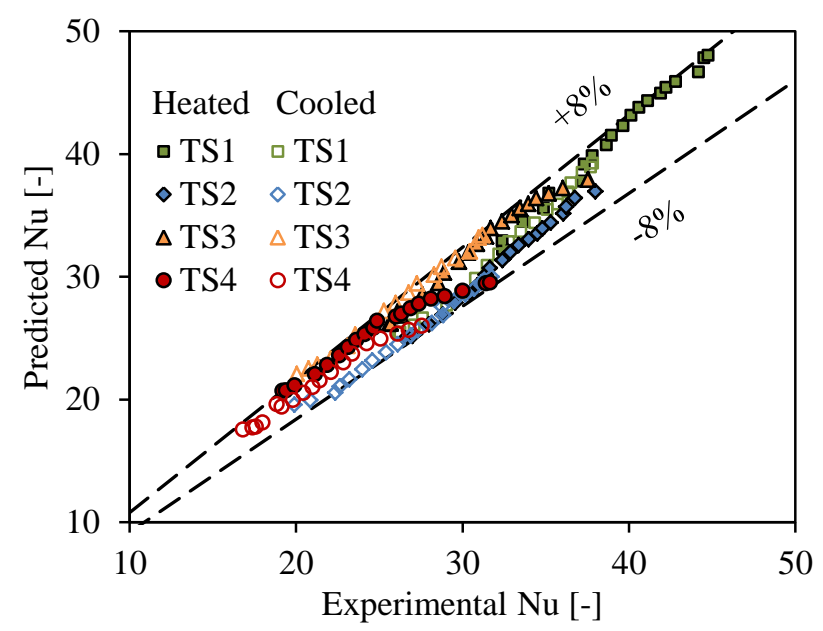

Figure 12: $\quad$ Comparison between experimental and predicted Nusselt numbers results

\subsection{Coefficients and exponents for the friction factor correlation}

It was mentioned that the isothermal case for friction factors was included in this investigation for referencing purposes. Therefore, its correlation was developed first. The diabatic cases were then developed, based on the isothermal correlation. The correlation for predicting isothermal friction factors is given in the Equation (21).

where

$$
C_{\text {iso }}=2.784 \lambda^{2}-717.574 \lambda+46425.43
$$

and

$$
m=-0.00357 \lambda+1.721
$$

The isothermal annulus correlation is developed for transitional flow regime cases with $1400 \leq \operatorname{Re} \leq 2500,64 \leq \lambda \leq 114$. The agreement between the experimental results and the proposed correlations was good, with $95 \%$ of the data points within a $\pm 7 \%$ error band.

Expressions for the coefficient and exponent in Equation (22) for the heated and cooled annulus cases were obtained as: 
For heated annuli:

$$
\begin{aligned}
& C_{d}=46.6 \times 10^{6}\left(\mathrm{Gr}^{0.01} \operatorname{Pr}^{2.9}\right)^{-3.12} \\
& z=3.8 \times 10^{-3}\left(\mathrm{Gr}^{0.01} \operatorname{Pr}^{2.9}\right)-0.88
\end{aligned}
$$

For an applicable range of $1400 \leq \mathrm{Re} \leq 2500,115 \leq \mathrm{Gr}^{0.01} \operatorname{Pr}^{2.9} \leq 160,1.35 \leq \mu_{b} / \mu_{i w} \leq 1.5$ and $64 \leq \lambda \leq 144$.

For cooled annuli:

$$
\begin{gathered}
C_{d}=10.95\left(\operatorname{Gr}^{0.01} \operatorname{Pr}^{2.9}\right)^{0.19} \\
z=-0.14 \times 10^{-3}\left(\operatorname{Gr}^{0.01} \operatorname{Pr}^{2.9}\right)-0.45
\end{gathered}
$$

For an applicable range of $1400 \leq \operatorname{Re} \leq 2500,60 \leq \mathrm{Gr}^{0.01} \operatorname{Pr}^{2.9} \leq 82,0.65 \leq \mu_{b} / \mu_{i w} \leq 0.69$ and $64 \leq \lambda \leq 144$.

The exponents for Grashof and Prandtl numbers were done iteratively to reduce the root means sqare difference of predicted friction factor values compared to the experimentally obtained values.

Figure 13 shows the comparison between the experimental and predicted friction factors for the heated and cooled annulus cases. The agreement between the experimental results and the proposed correlations was good, with $93 \%$ of the data points within a $\pm 8 \%$ error band for a heated case, and all the data points within a $\pm 8 \%$ error band for a cooled case. 


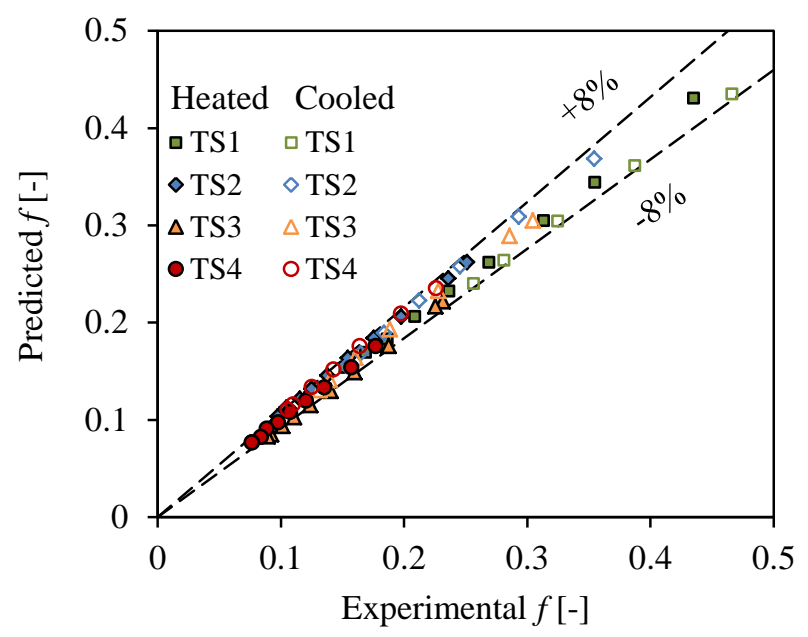

Figure 13: $\quad$ Comparison between experimental and predicted friction factor results.

\section{Conclusion}

The transitional flow regime for annular flow associated with mixed convection and developing flow was experimentally investigated in four test sections with the same axial length, but varying annular diameter ratio and annular gap dimensions. The tests were done for isothermal adiabatic and diabatic processes. The diabatic process involved both the cooling and heating of the annular fluid. The wall boundary conditions for the diabatic process were an approximately uniform wall temperature on the inner surface, and an isothermal condition on the outer surface of the annular passage.

A dimensionless annular geometric parameter, $\lambda$, representing the annular dimensions, was proposed. Both the annular geometric parameter and the direction of the heat flux (heating and cooling the annular fluid) influenced the lower and upper Reynolds number limits of the transitional regimes, heat transfer coefficients and friction factors. The Reynolds number span of the transitional flow regime decreased as $\lambda$ increased. For a specific $\lambda$ value, the Reynolds number spans of the transitional flow regime for cooled case were longer than for the heated case. The Nusselt numbers and friction factors were higher for smaller values of $\lambda$ 
than for larger values. The Nusselt numbers were higher for the heated case than for the cooled case, however the friction factors were higher for the cooled case.

New correlations for the Nusselt number and the friction factor in the transitional flow regime are proposed. The Nusselt number correlation for both the heated and cooled annulus cases predicts all the experimental data points within a $\pm 8 \%$ error band. The friction factor correlation for the heated annulus case predicts $93 \%$ of the experimental data within a $\pm 8 \%$ error band, while for the cooled case, it predicts all the experimental data within a $\pm 8 \%$ error band.

\section{References}

[1] H.K. Dawood, H.A. Mohammed, N.A.C Sidik, K.M. Munisamy, M.A. Wahid, Forced, natural and mixed-convection heat transfer and fluid flow in annulus: A review, International Communications in Heat and Mass Transfer 62 (2015) 45 - 57.

[2] J.P. Meyer, Heat transfer in tubes in the transitional flow regime, in: Proceedings of the Fifteenth International Heat Transfer Conference, 2014, Paper KN03.

[3] W. Nunner, Heat transfer and pressure drop in rough tubes, VDI - Forscchungsheft 55B (1956) $5-39$.

[4] N.T. Obot, E.B. Esen, T.J. Rabas, The role of transition in determining friction and heat transfer in smooth and rough passages, International Journal of Heat Mass Transfer $33(1990) 2133-2143$.

[5] J.G. Withers, Tube-side heat transfer and pressure drop for tubes having helical internal ridging with turbulent/transitional flow of single phase fluid: Part 1 - Single-helix ridging, Heat Transfer Engineering 2 (1980) 48 - 58. 
[6] R.M. Manglik, A.E. Bergles, Heat transfer and pressure drop correlations for twistedtape inserts in isothermal tubes: Part 1 - Laminar flows. Journal of Heat Transfer 115 (1993) $881-889$.

[7] J.A. Olivier, J.P. Meyer, Single-phase heat transfer and pressure drop of the cooling of water inside smooth tube for transional flow with different inlet geometries, American Society of Heating, Refrigirating and Air-conditiong Engineers 16 (4) (2010) 476 496.

[8] M. Everts, J.P. Meyer, Heat transfer of developing flow in the transitional flow regime, in: Proceedings of the First Thermal and Fluid Engineering Summer Conference, 2015, Paper 12660.

[9] M. Everts, J.P. Meyer, Heat transfer of developing flow in the transitional flow regime of solar receiver tube, in: Proceedings of the Third Southern African Solar Energy Conference, 2015 , pp. $224-229$.

[10] R.K. Shah, A.L. London, Laminar flow forced convection in ducts. Academic Press, New York, 1978.

[11] N. Hattori, Combined free and forced convection heat transfer for fully developed laminar flow in horizontal concentric annuli (numerical analysis). Japan Society of Mechanical Engineers Transactions 45 (1979) 227 - 239.

[12] S. Kotake, N. Hattori, Combined free and forced convection heat transfer for fully developed laminar flow in concentric annuli, International Journal of Heat and Mass Transfer 28 (11) (1985) $2115-2120$.

[13] J. Dirker, H. Van der Vyver, J.P. Meyer, Convection heat transfer in concentric annuli, Experimental Heat Transfer 17 (2004) 19 - 29. 
[14] F.P.A. Prinsloo, J. Dirker, J.P. Meyer, Heat transfer and pressure drop characteristics in the annuli of tube-in tube heat exchangers (Horizontal lay-out), in: Proceedings of the Fiftheenth International Heat Transfer Conference, 2014, Paper 9225.

[15] W. R. Van Zyl, J. Dirker, J.P. Meyer, Single-phase convective heat transfer and pressure drop coefficients in concentric Annuli, Heat Transfer Engineering 34 (13) (2013) $1112-1123$.

[16] F.W. Dittus, L.M.K Boelter, University of California, Berkeley, Publications on Engineering 2 (1930) $329-353$.

[17] T. Hung Nguyen, P. Vasseur, L. Robillard, S.B. Chandra, Combined free and forced convection of water between horizontal concentric cylinders. Journal of Heat Transfer, 105 (1983) 498-504.

[18] N. Islam, U.N. Gaitonde, G.K. Sharma, Mixed convection heat transfer in the entrance region of horizontal annuli, International Journal of Heat and Mass Transfer 44 (11) (2001) $2107-2120$.

[19] S. Mirmasoumi, A. Behzadmehr, Numerical study of laminar mixed convection of a nanofluid in a horizontal tube using two-phase mixture model, Applied Thermal Engineering 28 (7) (2008) $717-727$.

[20] M.R. Mokhtari, A. Akbarinia, M. Shariat, F. Talebi, R. Laur, Two phase mixed convection $\mathrm{Al}_{2} \mathrm{O}_{3}$-water nanofluid flow in an annulus, International Journal of Multiphase Flow 37 (6) (2011) 585 - 595.

[21] M. Izadi, M.M Shahmardan, A. Behzadmehr, Richardson number ratio effect on laminar mixed convection of a nanofluid flow in an annulus. International Journal of Computational Methods in Engineering Science and Mechanics 14 (4) (2013) 304 316. 
[22] Mohammed, H.A., Campo, A. and Saidur, R., Experimental study of forced and free convective heat transfer in the thermal entry region of horizontal concentric annuli. International Communication in Heat and Mass Transfer, 2010. 37: p. 739 - 747.

[23] M. Ciampi, S. Faggiani, W. Grassi, G. Tuoni, Mixed convection heat transfer in horizontal, concentric annuli for transitional flow conditions, International Journal of Heat and Mass Transfer 30 (5) (1987) $833-841$.

[24] G. Lu, J. Wang, Experimental investigation on flow characteristics in a narrow annulus, Heat and Mass Transfer 44 (4) (2008) 495 - 499.

[25] G. Lu, J. Wang, Experimental investigation on heat transfer characteristics of water flow in a narrow annulus, Applied Thermal Engineering 28 (1) (2008) 8 - 13.

[26] J.P. Meyer, J.A. Olivier, Heat transfer and pressure drop characteristics of smooth horizontal tubes in the transitional flow regime, Heat Transfer Engineering 35 (14-15) (2014), $1246-1253$.

[27] J.P. Abraham, E.M. Sparrow, W.J. Minkowycz, Internal-flow Nusselt numbers for the low-Reynolds-number end of the laminar-to-turbulent transition regime, International Journal of Heat and Mass Transfer 54 (2011) $584-588$.

[28] S.W. Churchill, Comprehensive correlating equations for heat, mass, and momentum transfer in fully developed flow in smooth tubes, Industrial Engineering Chemistry Fundamentals 16 (1) (1977) 109 - 116.

[29] L.M. Tam, A.J. Ghajar, Transitional heat transfer in plain horizontal tubes, Heat Transfer Engineering 27 (5) (2006) 23 - 38.

[30] M. Everts, R.S. Ayres, F.M. Houwer, C.P. Vanderwagen, N.M. Kotze, J.P. Meyer, The influence of surface roughness on heat transfer in the transitional flow regime, in: Proceedings of the Fifteenth International Heat Transfer Conference, 2014, Paper 8338 
[31] J.P. Abraham, E.M. Sparrow, J.C.K. Tong, Heat transfer in all pipe flow regimes laminar, transitional/intermittent, and turbulent, International Journal of Heat and Mass Transfer 52 (3-4) (2009) $557-563$.

[32] V. Gnielinski, Heat transfer coefficients for turbulent flow in concentric annular ducts, Heat Transfer Engineering 30 (6) (2009), 431 - 436.

[33] V. Gnielinski, A new calculation procedure for the heat transfer in the transition region between laminar and turbulent pipe flow (Ein neues Berechnungsverfahren für die Wärmeübertragung im Übergangsbereich zwischen laminarer und turbulenter Rohrströmung). Forschung im Ingenieurwesen 61 (9) (1995) 240 - 248.

[34] V. Gnielinski, On heat transfer in tubes. International Journal of Heat and Mass Transfer 63 (2013) $134-140$.

[35] Rayle, R.E., Influence of orifice geometry on static pressure measurements. MS Thesis, Massachusetts Institute of Technology, Boston, MA, 1949.

[36] A.J. Ghajar, K.F. Madon, Pressure drop measurements in the transition region for a circular tube with three different inlet configurations. Experimental Thermal and Fluid Science 5 (1) (1992) $129-135$.

[37] J. Dirker, J.P. Meyer, D.V. Garach, Inlet flow effects in micro-channels in the laminar and transitional regimes on single-phase heat transfer coefficients and friction factors, International Journal of Heat and Mass Transfer 77 (2014) 612 - 626.

[38] C. O. Popiel, J Wojtkowiak, Simple formulas for thermophysical properties of liquid water for heat transfer calculations (from $0^{\circ} \mathrm{C}$ to $150^{\circ} \mathrm{C}$ ), Heat Transfer Engineering, 19(3) (1998) $87-101$.

[39] R.J. Moffat, Describing the uncertainty in experimental results, Experimental Thermal Fluid Science 1 (1) (1988) 3-17. 
[40] G.K. Filonenko, Hydraulic resistance of pipes (Hydraulilischer widerstand von rohrleitungen). Teploenergetika 1 (4) (1954) $40-44$.

[41] V. Gnielinski, Berechnung des druckverlustes in glatten konzentrischen ringspalten bei ausgebildeter laminarer und turbulenter strömung. Chemie Ingenieur Technik 79 (2007) $91-95$.

[42] V. Gnielinski, Turbulent heat transfer in annular spaces - A new comprehensive correlation, Heat Transfer Engineering 36 (9) (2015) 787 - 789.

[43] A.J. Ghajar, L.M Tam, Effect of inlet geometry and heating on the fully developed friction factor in the transition region of a horizontal tube, Experimental Thermal and Fluid Science 15 (1) (1997) $52-64$.

[44] P. K. Swamee, N. Aggarwal, V. Aggarwal, Optimum design of double pipe heat exchanger, International Journal of Heat and Mass Transfer 51 (9-10) (2008) 2260 2266.

[45] J. Dirker, J.P. Meyer, Convective heat transfer coefficients in concentric annuli, Heat Transfer Engineering 26 (2) (2005) 38 - 44.

[46] E. S. Davis, Heat Transfer and Pressure Drop in Annuli. American Society of Mechanical Engineers Transactions 65 (1943) 755 - 760.

[47] A.S. Foust, G.A. Christian, Non-boiling heat transfer coefficients in annuli, American Institute of Chemical Engineers Journal 36 (1940) 541 - 554.

[48] C.C. Monrad, J.F. Pelton, Heat Transfer by Convection in Annular Spaces. American Institute of Chemical Engineers Journal 38 (1942) $593-611$. 